\title{
海绵城市市政给排水规划设计分析
}

陈平

四川远通规划设计有限公司

DOI:10.32629/btr.v2i10.2568

[摘 要] 洪涝问题已成为目前很多城市发展的普遍问题,该问题的出现不仅对城市各项基础设施带来了影响,同时也为人们 的生活构成了威胁。为此,海绵城市理念被逐渐提上日程,并通过合理应用,对市政给排水系统实行了优化, 以改善城市的洪港问 题,促进城市的良好建设和发展。

[关键词] 海绵城市; 市政给排水系统; 城市洪漟

如今, 海绵城市理念在城市建设中广泛应用。海绵城市 建设中十分重视给排水设施的创新, 合理利用自然环境实现 排水规划和自然环境的高度融合, 高效利用雨水, 从而增大 水资源利用率, 减轻水资源污染问题。故而海绵城市市政给 排水规划设计也受到了人们的高度重视。

\section{1 海绵城市理论分析}

海绵城市理论主要指城市如海绵可适应环境的多重变 化, 也可面对自然灾害所产生的负面影响。其弹性较大, 降雨 时可起到收集、渗透和净化雨水的作用, 还可储存、释放并 利用雨水, 进而达到预防城市内涝, 净化市内空气的目的。

海绵城市理论以生态优先为基本原则, 在发展中重视城 市与自然的协调发展, 保证城市排水效果, 在自然积存的基 础上调蓄削峰, 加大对径流量的控制力度, 有利于恢复城市 的水生态, 优化水循环, 减轻水体污染。海绵城市建设中高度 重视全过程控制, 而这对水资源生态循环的形成也起到了关 键作用。

\section{2 城市市政给排水规划设计的内容}

2. 1 给水系统规划设计

市政工程给排水系统规划设计中, 工作人员应结合当地 的水文条件和地质条件, 掌握当地降水量和水资源分布概况, 在降水量较小的时节建设用水量较小的工程, 在降水量丰富 的时节建设涌水量较大的工程。同时, 明确当地是否存在水 资源分布不均的问题, 然后采取多种措施实现水资源的优化 配置, 完善给水系统规划设计。

\section{2排水系统规划设计}

市政给排水系统规划设计中, 设计人员需结合实际采取 不同的设计方式。设计者先要制定科学的防洪排涝方案, 设 计前, 了解当地实际情况, 并以此为基础收集设计中所需的 资料。设计中, 全面考虑污水排放, 排水系统设计的过程中要 结合城市布局和污水系统的运行标准处理, 并将标准引入到 原材料使用方案当中。采取上述方式可显著提高排污系统的 运行效率。最后, 采取多种措施明确城市中的污水量, 采取合 理的计算方法计算城市的污水量, 以污水量为基础确定排水 系统设计的各项参数。

\section{3 海绵城市下市政给排水设计}

\section{1 车行道}

车行道是市政工程建设中较为重要的组成部分, 在市政 给排水设计中, 需要对车行道的功能和作用予以明确掌握, 运用合理材料和技术来提升车行道的透水性能, 降低因雨水 等的过多堆积对车行道结构质量带来影响, 进而增大车辆行 驶的危险系数。基于此, 在车行道市政给排水设计中, 融入海 绵城市理念是尤为重要的。海绵城市理念的应用实现了透水 性路面施工, 达到了减少径流量的目的。在实际施工作业中, 道路上层采用了透水性沥青混凝土, 而下层采用了非透水性 材料, 避免雨水堆积对路基结构的影响, 且上层的透水性也 能够直接将雨水引入到周边的绿化带或检查井中, 从而增大 雨水循环利用率。不过要想实现雨水两侧外引, 需要对车行 道的坡度予以合理设置。一般情况下横向坡度控制在1-1.5\% 之间, 纵向坡度控制在0. 3-6\%之间。

\section{2 人行道设计}

人行道是市政道路中的重要组成部分, 人行道一方面可 方便市民的日常出行, 另一方面也可有效发挥出市政工程的 积极作用。所以, 在人行道设计中合理应用海绵城市的理念, 也有着较为深远的作用和价值。传统的市政工程人行道设计 中, 普遍采用不透水路面。如遇暴雨天气则会出现路面积水 和路面湿滑的问题, 影响人们的日常出行, 并且也会威胁交 通安全。融入海绵城市理念后, 人行道可选择透水性较强的 材料, 其可确保雨水天气时, 多余的雨水可及时进入地下, 避 免城市道路出现严重的积水问题, 而且也可起到调节人行道 路面温度及湿度的作用。

再者, 完善的排水系统还可增加地下水源。若在工程建 设中受其他因素的影响, 土壤的透水性无法满足要求, 则应 结合工程实际设置排水管, 改善市政道路排水的效果。这里 需要格外注意的是, 设置排水管时务必采取有效措施加大对 坡度的控制力度。

\section{3绿化带设计}

在建设海绵城市的过程中, 需与城市建设的基本原则高 度贴合。市政排水规划工作中, 要全面考量自然环境因素对 工程的影响。设置绿化带一方面可起到美化城市环境的作用, 另一方面也能够合理地应用市政水资源。海绵城市背景下的 
市政给排水工程设计中, 绿化带占据着极为关键的地位。绿 化带具有强渗透性, 且绿植也可发挥其缩水的功能, 采取多 种措施合理规划绿化带, 可提高雨水的利用率, 同时也更好 地展现出海绵城市的优势和作用。

首先绿化带可收集雨水。为了更加便捷地收集雨水, 设 计者可在绿化带旁设置若干固定的雨水沟, 雨水沟不得阻碍 城市交通运行。透水地面中, 雨水可以地表径流的方式汇集 于绿化带雨水口, 且其通常设置于路面下方 $15-20 \mathrm{~cm}$ 。另外, 将雨水口设置在绿化带种植土与道路中间, 且注重分布的均 匀性, 增大绿化带和雨水管道系统的衔接密度。并在绿化带 中设置溢流系统, 连接雨水收集系统, 这样在绿化带中积存 过多雨水时, 可直接排放至排水管道当中。

其次是水体过滤。设计者需自渗入层考量水体过滤的设 置方式。于底层安装渗水管, 上部铺设过滤砂石层, 然后在上 部铺设薄土层, 该铺设方式可借助多层过滤的方式保证雨水 过滤的效果, 改善地下水的水质。

再次是缓排滞蓄。设计人员需在绿化带中设置若干明沟, 引导雨水流入明沟, 如降水量较大, 雨水可在明沟的过度下 顺利进入地下, 雨水经沉淀后可再次储存。

最后是排放。如城市降水量超出其承受范围, 雨水口和 明沟等无法及时排出路面的积水, 应直接连接海绵城市排水 管道和市政排水管道, 从而提高排水的效率。城市周边如有 衔接的绿化带, 则需采取有效措施加强设计的科学性与合理 性, 从而增大市政道路的存水能力。采取分流措施后可有效 减少城市路面积水, 改善城市交通状况。

再者, 在设计的过程中, 设计人员还要利用源头渗透技 术加强雨水排放的效果, 采用中途渗透技术实现雨水收集。 且在利用城市绿地衔接区域的过程中也有效减轻了城市的 积水压力, 增大了城市的雨水净化能力, 达到补充地下水, 保 护水资源的目的。

3. 4 附属设施设计

路缘石通常位于路面和其他构件设备的中间, 在马路分 隔带、路面边缘等区域十分常见。路缘石主要分为平缘石与 立缘石, 高度是分类的主要依据, 平缘石一般与地表的高度相 同, 其可避免雨水的过度堆积, 将雨水导流至绿化带, 而立缘 石的高度则更高, 其能够以较快的速度将雨水导入绿化带。

雨水口是收集城市道路路面雨水径流的重要设施, 同时 其也成为了雨水收集的起点。以传统雨水口为基础设置截污 装置, 以截污铁䔣来替代传统的葲子。为了简化清晰流程,
在装置内设置了滤网防堵塞侧壁进水排水帽。雨水蓖子打开 后, 冒出的烟就能够阻止杂物进入到雨水口当中, 从而减少 雨水口堵塞和污水回流等问题。

路肩边沟的设计也十分关键, 路面设计要求较高, 在设 计路肩边沟的过程中普遍采用非渗透性材料。混凝土水泥是 最为常见的原材料, 由于材料特性的影响, 雨水无法得以充 分的渗透与沉淀, 视觉感官效果也并不理想。因此, 在海绵城 市设计的过程中, 应在周围建设沟渠, 也可在周边种植植物, 进而达到净化和储存雨水的目的。

\section{4 市政道路给排水设计中需要注意的问题}

海绵城市建设和发展的过程中, 多部门协作是工程建设 的基础。在市政道路给排水设计中, 禁止破坏原有的基础设 施, 设计前需明确城市原有排水系统的分布和运行概况, 仔 细分析和研究现有设备, 总结当前存在的主要问题, 明确工 程施工中产生的负面影响, 然后针对可能出现的突发事件, 采取有效的应对措施, 保证工程施工的顺利开展。

为了不断提高排水和进水的效率, 可采取下凹的方式设 置进水口, 并结合道路的纵坡调整进水口的各项参数。为了改 进设计和施工的效果, 还可设置科学完善的防冲刷设施。合理 连接溢流排放系统与排水系统, 从而建立完善的水循环系 统。对于内涝频率较高的区域, 可设置预警系统, 同时建立警 示标志, 有效降低交通事故发生率。另外, 在建设的过程中务 必高度重视竣工验收和监督, 充分顺应工程建设规范的基本 要求。且在运营的过程中做好养护和检修工作, 加强面层的 完整性, 彻底强化交通及排水设施建设的整体效果。

\section{5 结束语}

现阶段, 我国经济发展水平明显提高, 社会对水资源的 需求也明显增大。因此, 在社会生产和生活中, 一方面要建立 节约用水的意识和理念, 另一方面需将城市的建设重点放在 水资源循环利用上。海绵城市可高度满足城市发展的各项需 求, 这使得海绵城市成为了城市发展的主流趋势, 推动现代 化城市建设的可持续前行。

[参考文献]

[1]刘鹏.海绵城市在市政道路设计中的应用分析 [J].居 舍,2019,(17):107.

[2]郭维. “海绵城市”理念在市政排水设计中的应用 [J]. 住宅与房地产,2019,(09):48.

[3]王思雯.生态城市背景下市政给排水规划设计的重要 性及要点探析[J].工程技术研究,2019,4(10):184-185. 